\title{
Socialisation Process, Power Relations and Domestic Violence: Marginal Voices of Assamese Women
}

Dr Polly Vauquline ${ }^{\dagger}$

\section{Abstract}

Domestic violence is an evil that never dies. It is an indicator of inequality, injustice and discrimination of the social system. Though there is no justification for its existence in a civilized society, then why it is so difficult to root it out? Why does it persist to exist even after the prevalence of legal provisions to combat domestic violence? The causes maybe embedded on the facts that it involves intimate relationship on the one hand and exercise of power relations on the other. These power relations put women at disadvantaged positions, which are prominently gendered in nature.

Assam, a state in the north-eastern corner of India, is unique in its own distinction. It is a region with myriad communities with varied culture, ethnic and social background. Distinctive statistical differences of domestic violence exist among these communities. These variations may categorically be due to the nature of power relations in intimate relations among these communities, which is probed with the application of oral history method.

An effort is made through this study to explore the societal attitudes concerning power within intimate human relations. The focus of this paper is to search for the social beliefs attached with the power relations that have been governing them or promoting them in the form of social values, customs, rituals and traditions, which are the nucleus of domestic violence in Assamese society. This study intends to investigate the power relations amongst the different communities. Oral history method is applied to probe the socialisation process of the victims of domestic violence and to analyse how it creates power relations that caters to domestic violence. It gives a deeper understanding to the gendered nature of power in intimate relations. It illustrates that power relations is created through socialisation process and is a contributing attribute to domestic violence among spouses.

Key words: Power, Intimate Relations, Domestic Violence, Marginal Voices, Social Values, Assam

\footnotetext{
${ }^{\dagger} \mathrm{HoD}$, Associate Professor, Department of Women's Studies, Director, Women's Studies Research Centre, Gauhati University, Guwahati-14, Assam, India, Email: pollyvauquline@yahoo.co.in

(C) 2015 Vauquline. This is an Open Access article distributed under the terms of the Creative Commons Attribution License (http://creativecommons.org/licenses/by/2.0), which permits unrestricted use, distribution, and reproduction in any medium, provided the original work is properly cited.
} 


\section{Introduction}

Violence against women (VAW) is a form of human rights violation (Das et al, 2015a, forthcoming; Jaisingh, 1995). ${ }^{1}$ The commonest form of VAW is the intimate partner violence, which occurs within the private domain (AhmedGhosh, 2004; Bhattacharyya 2015; Chaudhary, 2013; Das et al., 2015a, forthcoming; Ragavan et al., 2015; Samarasekera and Horton, 2015; Umberson et al. 1998; Yeasmeen, 2014; Vauquline, 2007). Consistent efforts and grassroots work of women's organisations drew out VAW from the private domain to public attention and state accountability (Bhattacharyya, 2015; Das et al., 2015a, forthcoming; Samarasekera and Horton, 2015). However, it continues to persist as an evil practice in the society and becoming difficult to be rooted out. It is causing countless pain, fear and misery to women in almost every country of the world (Fulu et al., 2013; Jewkes et al., 2013; Das et al., 2015a, forthcoming; Bhattacharyya, 2015). It is not merely an individual's act of misconduct but a 'deeply rooted structural relationship of inequality between man and woman' (United Nation, 2006) which are perpetrated by different cultural practices such as son preference, child marriages, food denial, dowry demand, etc. The role of culture, the traditional practices and the rituals associated with it acts as causal factors for VAW and, therefore, must be investigated as a social process of power relations than as mere sets of beliefs (Bhattacharyya, 2009; 2013; 2015; Chakrabarty, 2002). This ultimately creates an exploitative gender-based hierarchical society (Karlekar, 2008; Das et al., 2015 a, forthcoming). Existence of strong legal provisions is no doubt essential, but understanding the internal dynamics of Indian families through the mechanism of socialisation process is equally important. In the said context, it is the purpose of this research to understand the gendered power-relations in

\footnotetext{
${ }^{1}$ Violence Against Women Information, Amnesty International, available at: http://www.amnestyusa.org/our-work/issues/women-srights/violence-against-women/violence-against-womeninformation (accessed 27 October 2015)
}

intimate relationships among five Assamese women residing in the city of Guwahati, Assam. The findings suggest that the unequal power relations created through cultural training (Bhattacharyya, 2009, 2013; Chakrabarty, 2002) is one of the key contributing factors of Domestic Violence (DV) in intimate partnerrelations.

The research begins with a brief background. Following this, I aim to probe the connections between the socialisation process, power relations and DV. Then, I outline the rationale of the study and the methodology deployed, which is followed by the findings.

\section{Background}

In 1871, Alabama, in the USA became the first state to retract the right of the husbands to beat their wives (Fagan, 1996: 7). Again, in 1882, Maryland (USA) became the first state to impose legal provisions on wife-beating and made it punishable according to the law (Hart, 1991). The need for protection of the rights of women gained global recognition during the International Decade of Women (1975-1985) and was steadily gaining momentum since then (United Nation Observances, A/RES/3520 (XXX), 1975).This recognition became an international law in 1979, when the UN General Assembly adopted the Convention on the Elimination of All Forms of Discrimination against Women (CEDAW). It established a universal set of standards and principles that are intended to serve as a template for shaping national policies towards the long-term goal of eliminating gender discrimination. India became signatory to the Convention in 1993 and ratified CEDAW and committed itself to work for the elimination of all types of discrimination against women.

In the Indian context, despite the existence of strong legal provisions against DV, it is on the rise. According to National Crime Records Bureau (NCRB), Ministry of Home Affairs, in India the rate of occurrence of dowry death (reported cases) was 1.4\% during the year 2014 $(8,455$ cases). As for cases of torture by husband and in-laws, under section 489-A Indian Penal Code (IPC), are concerned, the 
rate of its occurrence was $20.5 \%$ in the year $2014(1,22,877$ cases). The cases under the Dowry Prohibition Act have increased by $1.7 \%$ during the year 2014 as compared to 10,150 cases in 2013. A total number of 426 cases of DV under the Protection of Women from Domestic Violence Act, 2005 were registered during the year 2014, which is an increase of $0.1 \%$ from 2013 In the context of Assam, in 2014 , there has been a large increase in the rate of registered cases under 489-A IPC (9626 cases, $62.1 \%){ }^{2}$ Incidences of dowry deaths (189 cases, $1.2 \%$ ) and cases under Dowry Prohibition Act are also showing rising trends (92 cases, 0.6 $\%)$.

In India, VAW and more so, DV needs to have a social and cultural understanding. The uniqueness of Indian society is that it is progressive and embedded with rich tradition and cultural values. However, at the same time, there are various practices, which are laden with patriarchal values (Bhattacharyya, 2009; 2013), those may at times adhere to DV in a society (Bhattacharyya, 2015; Ragavan et al., 2015).

DV can be considered as a worst form of violence on women because these are the atrocities which women encounters within the four walls of her home where she is supposed to feel the safest (Bhattacharyya, 2015; Das et al., 2015 a, forthcoming ;Fulu et al., 2013; Jewkes, 2013; Ragavan et al., 2015). These are aggressions and violent behaviours, which are used by the partner as a form of power or control over the other, very often male over the female. It is observed that there are various social practices that patronises man's dominance on the life of the women and often legitimise the demonstrations of masculinity in different social practices (Bhattacharyya, 2015; Das et al., 2015a, forthcoming; Ragavan et al., 2015). On the other hand, the women are created to be feminine and thereby, submissive and docile (Bhattacharyya, 2009, 2013, 2015; Dube, 1988). These inequalities built on the basis of gender can be considered as the

\footnotetext{
${ }^{2}$ Figures in brackets refer to the number of reported cases and the rate of occurrence respectively.
}

primary factors of DV, which also illustrates the other types of dynamics associated with it (Bhattacharyya, 2015).

\section{Connecting Socialisation Process, Power Relations and Domestic Violence}

The very definition and understanding of a home as a place where people co-habit in peace and harmony is increasingly becoming questionable in today's context. With the increase in the number of incidences of DV, the 'home', the very supposition that the entire members feel safe and are at peace, is at stack (Bhattacharyya, 2009; Krishnan, 2005). It has now complex and multivalent meanings. Along as a site of privacy and freedom of expression, it has also become a site of oppression (Bhattacharyya, 2009; Domosh and Seager, 2001; Krishnan, 2006). According to BBC crimes analysis, it is estimated that 'about once every five minutes an incident of DV is reported in India', under the section 489-A IPC. ${ }^{3}$ The number may be more as it represents only the reported cases. Therefore, for many women, home is a battleground, not a safe haven. Violent acts in married couples when understood in the context of "family systems", it is viewed as instances endemic to almost in all forms of societies, developed, developing and under developed, in varied proportion (AhmedGhosh,2004;Bhattacharyya,2015;Choud hury, 2013; Das et al., 2015a, forthcoming; Fulu et al., 2013; Jewkes et al., 2013; Ragavan et al., 2015; Samarasekera and Horton, 2015; Umberson et al. 1998; Yeasmeen, 2014; Vauquline, 2006), which needs to be condemned (Brush, 1990; Yeasmeen, 2014). Earlier in 1987, Straus had contributed to our understanding of the household as a dangerously violent place for many people (Straus, 1987; Krishnan, 2005; Dalal \& Lindqvist, 2012), which continues to be so even today (Bhattacharyya, 2015; Das et al., 2015a, forthcoming ; Fulu et al., 2013; Jewkes et al., 2013; Ragavan et al., 2015). Until recently, in most parts of the world, a husband enjoyed a legal right to his wife's body (Arthur and Clark,

\footnotetext{
${ }^{3}$ Available at: http://www.bbc.com/news/world-asiaindia-29708612 (accessed 30 September 2015)
} 
2009; Bhattacharyya, 2015; Das et al., 2015a, forthcoming; Ghosh, \&Choudhuri, 2011). When we analyse the data provided by NCRB (2014), a very disturbing image emerges. It reflects that of the total number of registered cases of crimes against women, violence occurring within the household in the form of DV, constitutes $58 \%$ of the total crimes against women. Again, there are far more incidences of DV, which are never reported (Bhattacharyya, 2015; Das et al., 2015a,forthcoming).

DV against women by men is often caused by the misuse of power and to control the women within the context of male privilege. Weber (1968) states that 'power is connected to authority, domination, exploitation and is an entity that an individual or group may possess' (Clegg, 1975: 57). Michel Foucault in his work, History of Sexuality, while describing power states that '[p]ower must be understood in the first instance as the multiplicity of force relations immanent in the sphere in which they operate and thus constitute their own organization: as the process which, through ceaseless struggle and confrontations, transforms, even reverses them; as a support which these force relations find in one another, thus forming a chain or a system' (Foucault, 1977: 94). He argued that, 'power is not a thing acquired but rather exists in its exercise. Moreover, power relations are not separate from other relations but contain with them' (Hartsock, 1999: 164). Thus, power can be linked to violence, both at individual and collective levels. The men operate this privilege on the women to maintain a situation of dominance, where men have the power over the women. ${ }^{4}$ The very definition of DV as "a pattern of abusive behaviour in any relationship that is used by one partner to gain or maintain power and control over another intimate partner" (United States Office on Violence against Women) also describes the power relations attached with the act of domestic violence (Babbel, 2011). Abusers

\footnotetext{
${ }^{4}$ If There is Violence Break the Silence, http://www.redcarcleveland.gov.uk/rdv.nsf/Web?ReadForm\&id=C1390898 BCAC10A08025771C004EDE3E
}

behave violently to get what they want and gain control over the women. Violence is an ultimate resource used to derive power within relationships. Recent work has examined the mechanisms through which this structural inequality influences domestic assaults (Anderson, 1997; AhmedGhosh, 2004).

Johnson and Ferraro(2000)also suggested that a promising development has been worked upon violence as a mode of control, in heterosexual relationships as well as in samegender relationships. Seemingly, feminist scholars argue that DV is rooted in gender and power and represents men's active attempts to maintain dominance and control over women (Anderson, 1997; Krishnan, 2005; Watto, 2009). The heart of the debate centres on the relative importance of patriarchy in the etiology of DV. Researchers argue that violence is part of a system of coercive controls through which men maintain societal dominance over women (AhmedGhosh, 2004; Das et al., 2015 a, forthcoming; Dobash \& Dobash, 1979; Martin, 1976; Stark \& Flitcraft, 1996, Ragavan et al., 2015). Again, according to the Societal Structure Theory, DV is 'caused by an underlying power imbalance that can be understood only by examining society as a whole' (Wolfe and Jaffe, 1999: 137). It emphasises on patriarchy or male domination over women and children through physical, economic, and political control. DV depicts women's inequality in the culture and strengthens this reality by various institutions. ${ }^{5}$

Individual in a society goes through a process of socialisation from their childhood to their adulthood. It is a lifelong process (Chakrabarty, 2002; Pilcher and Whelehan, 2004). Dictionary.com defines socialisation as 'a continuing process whereby an individual acquires a personal identity and learns the norms, values, behaviour and social skills appropriate to his or her social position. ${ }^{\prime 6}$ Several scholars propose that every

\footnotetext{
${ }^{5}$ Canadian Panel on Violence against Women. Changing the landscape: Ending violence-achieving equality (final report). Ottawa: Minister of Supply and Services, 1993. ${ }^{6} \mathrm{http}: / /$ dictionary.reference.com/browse/socialization
} 
member of the society, men or women, knowingly or unknowingly but actively construct gender through the social practices designed to differentiate men from women (Bhattacharyya, 2009; 2015; Chakrabarty, 2002; Connell, 1987; Segal, 1990; West \& Zimmerman, 1987). These social practices and behaviours construct and maintain the notion that men and women are different. It strengthens and patronises men's dominance in both a real and a symbolic fashion. The cultural depiction of the husband as breadwinner has supported, indulged and even encouraged greater rewards accorded to men in the workplace and in the family. It has also provided a social legitimacy to male power within the family, and provided men with a resource for demonstrating their masculinity (Bhattacharyya, 2009; 2013; 2015; Fulu et al., 2013; Ferree, 1990; Jewkes et al., 2013; Stark \&Flitcraft, 1996). On the other hand, the wife had her subservient but complimentary role as caretaker (Bhattacharyya, 2009; 2013; 2015; Domosh and Seager, 2001) and nurturer. Very often when men feel their masculinity is challenged or even otherwise, violence is a culturally appropriate means for men to exert dominance and control (Bhattacharyya, 2009; 2013; 2015; Campbell, 1993). Whereas, due to gender constructions of femininity as passive, supportive, and nurturing may discourage women from employing violence as a means to gain power in their relationships (Bhattacharyya, 2009; 2013; 2015; Campbell, 1993). Gender theory proposes that violence is a resource for constructing masculinity, and thus, the use of violence will have different meanings for women and men. Additionally, gender theory emphasise that DV will be affected by social processes that support men's societal dominance, such as cultural support for couplings in which men have greater resources than their female partners (Anderson, 1997). Social Learning and Development theory suggests that DV is a learned behaviour that is modelled, rewarded, and supported by families and/or the broader culture. (Emery and Laumann-Billings, 1998). Scholars also suggest that cultural support for violence facilitate domestic assaults (Bhattacharyya, 2015; Das et al., 2015a, forthcoming; Gelles \& Straus, 1988; Ragavan et al., 2015). These investigators analyse abuse of an intimate partner ("battering") as a social relation. They focus on relationships of domination rather than individual acts of violence (Brush, 1990).

Again, a growing body of work on gender (Dobash \& Dobash, 1979; Martin, 1976; Stark \& Flitcraft, 1996, AhmedGhosh, 2004; Ragavan et al., 2015) suggests that an adequate understanding of gender relations must entail concurrent analyses of power structures formed around race or ethnicity, social class, and sexuality (Connell, 1987; Segal, 1990). Many studies suggest that cultural constructions of masculinity and femininity are not monolithic. Rather, meanings of masculinity and femininity may differ among racial or ethnic groups (Majors \& Billson, 1992) and working and professional classes (Connell, 1987; Messerschmidt, 1993). Patriarchal family structures vary in their intensity from one society to another and for one sub-society over time (Arthur and Clark 2009).

Feminist sociologists contend that issues of gender and power are the ultimate root of intimate violence (Dobash \& Dobash, 1979; Stark \&Flitcraft, 1991; Yllo, 1993; Karlekar, 2008), but sociologists from other substantive traditions (e.g., family sociology) argue that patriarchy is just one variable in a complex assemblage of causes such as gender inequality, gender based discriminations, rigid segregation of gender roles, etc. (Gelles, 1993; Straus, Gelles \& Steinmetz, 1980; Tracy, 2007; Watto, 2009). Patriarchy may be one of the variables of the many cause of violence but can be understood as one of the major causes of DV. The power relation that often exists in home between the husband and the wife is promoted by the principles of patriarchy. So, power relations that prevails in intimate relations (married couples in the Indian context) can be attributed to patriarchy that have been endorsed through social values, traditional norms, cultural rituals and social practices attached to it (Bhattacharyya, 2009; 
2013; 2015; Das et al., 2015a,forthcoming; Tracy, 2007; Watto, 2009). These have been carried forward generation after generation through the process of socialisation by different agencies (Chakraborty, 2002; Bhattacharyya, 2009; 2013).

Since the 1970s and 1980s, understanding the power relationship between male and female and its consequences have been one of the major focus areas for the feminist scholars (Crowley, 1999). There have been continuous efforts by the scholars of women's and gender studies to provide explanations to DV through gender and women's perspectives. The next section discusses the rationale of the study.

\section{Rationale of the Study}

Scholars have framed up different strategies to combat DV, but new research on DV continues to emerge. One important measure to tackle DV is prevention strategy. It involves efforts to reduce the incidence of a problem before it occurs. It tries to implicate that as long as DV is disregarded as accepted behaviour by public attitudes and institutions, there is little chance of preventing it (Wolfe, 1999). Literature reveals that there are hidden forces, which nurtures unequal relations in a society and leads to DV (Choudhury, 2013; Yeasmeen, 2014). They are deep-rooted social beliefs attached with social values but promote power relations within the family, between husband and wife. They are at the same time upheld and promoted as social values through certain customs, rituals and traditions (Dube, 1988; see also; Bhattacharyya, 2009; 2015; Chakraborty, 2002).I argue that these values could be considered as nucleuses of DV in a traditional Assamese society.

Again, these are certain questions which calls for pondering like 'why do some people perpetrate acts of DV, and why do so many victims remain in abusive relationships?'(Umberson et al. 1998; AhmedGhosh, 2004; Vauquline, 2007; Ragavan et al., 2015). The Patriarchal Theory on family violence, which submits that, throughout history, males have dominated society and women were treated as men's possessions, can substantiate these (Bhattacharyya, 2009; 2013, 2015; Das et al, 2015a, forthcoming). These norms have historical roots that emphasise female subordination. There may be variations to the extent to which patriarchal norms remain intact. There is a need for investigating the evidence of the continuing presence of these practices that restrict women's freedom in society at large or within the family particularly. It will also provide answers to why women remained in abusive situations and continue to do so. Certain studies emphasise that due to psychological factors individualstypically women- intend to remain involved in abusive relationships (Bowker, 1983; Walker, 1984; Chaudhary, 2013; Ragavan et al., 2015). Historical understandings to the various aspects of DV will definitely unveil the unheard stories of the marginal voices of the victims of violence if probed through oral history method. In the light of these arguments, the primary objective of this research is to investigate how power relations are created through the process of socialisation, which in turn acts as a casual factor of DV.

\section{Methodology}

Qualitative in-depth studies have given insight on a range of issues such as women's supportseeking behaviour, intergenerational effects, the culture of silence, and the adherence to social norms that encourage tolerating, accepting, and even rationalising DV for the sake of preserving family honour (Bhattacharyya, 2015; Das et al., 2015a, forthcoming; Hassan 1995; Miller 1992; Jaisingh 1995; Koenig et al., 2006) and also for the sake of their siblings. Very few studies have been carried out to examine these issues from the perspective of the victims of violence. Focusing on these thoughts, an effort is being made in this study to probe into the lives of the victims of DV and their process of socialisation, in their childhood days and in other stages of their lives. It has been emphasised by social scientists that as social being every member of the society learn the social norms from different agents such as family, school, peer groups, religion and media, (Chakrabarty, 
2002). Different values are nurtured and learned consciously as well as sub-consciously through observation and by being active member of the society (Bhattacharyya, 2009; Chakrabarty, 2002). Along with the rich traditional values, women are also often taught through their socialisation process to be submissive, tolerant and docile. These gendered forms of socialisation where women are expected to be feminine, puts women in the receiving end in abusive situation such as DV (Vauquline, 2007).The values they have nurtured, consciously and even in their subconscious minds from different agents in their lifetime, which adhere to their abusive lives are investigated. An intergenerational exploration is carried out to gain an insight of the process of transferring of these customs, tradition, cultural and societal values from one generation to another, which are deep rooted in a traditional Indian society. It has provided a better understanding of the power relations between the husband and wife that continue to prevail in majority of the Indian families and also from where it begets (Bhattacharyya, 2015; Ragavan et al., 2015).

Oral history method using feminist perspectives are applied to probe into the lives of these women who have experienced DV. Feminists believe that the personal experience of every woman has worth and should be understood in all its complexity and richness (Dwyer and Limb, 2001; Bhattacharyya et al., 2011; Bhattacharyya and Vauquline, 2013). Feminists give emphasis to the social and political context of women's experience because their experiences are structured by gender (Thompson, 1992) that places them in disadvantaged positions. Again, there are voices and experiences of women, which are never recorded or even considered to have any historical significance and dangle within the margins or are completely invisible or silent in historical knowledge. Application of oral history method has provided a tool to hear these marginal and the unheard voices of these victims. Documenting women's oppression empowers the women, the historians and the women's movement and contributed to a very critical re-visioning of women's history (Gluck, 2011). Through oral history method, the 'normal' life of a woman is ruptured and the critical areas and the crisis that women encountered are exposed.

For this research, five cases are taken from Guwahati city (Table 1). All these women follow Hinduism as their faith but represent different ethnic groups. To study the inter-generational effects both mother and daughter were interviewed, Anuja and Anuja's mother; Susmita and Susmita's mother, Faguni. Since Minu's mother no longer exists, information regarding her mother was acquired from Minu herself regarding her socialisation process. One of them belongs to the Bodo community; ${ }^{7}$ two belongs to the Munda (tea tribe), while the other two belongs to general caste. The Bodo woman belongs to higher economic group, the general caste women are from middle economic group and the women from the tea tribe are from the lower economic group.

In oral history method, storytelling is one of the ways of availing information, which is a relatively new legitimated research method, in which the personal stories are collected from the individual (Biber \& Leavy, 2011: 131). Since DV is a sensitive issue and the victims, in most instances, are reluctant to reveal and hesitant to speak, it was essential for the author to carry out the interviews through multiple sittings, which was time consuming (Das et al., 2015a, forthcoming). During the interviews, two aspects were focused; their socialisation process and the instances of DV. The author (herself the interviewer) encouraged the respondents to speak about the instances of violence by their partner in the form of storytelling of their real life experiences. The interview/conversation was carried out in Assamese language. At the beginning of the interaction, the respondents were informed about the purpose of the study and due consent was provided to the author to record their interviews in audio recorder. The interviews were unstructured and were

\footnotetext{
${ }^{7}$ Bodos are the plain tribes and the earliest settles of Assam, India.
} 
primarily guided by the objectives of the study. In this study, the following research questions were probed to acquire understandings of the cultural factors of DV through the narratives of the victims of DV of their bygone days. How are women socialised by different agents that adhere to the power relations and act as factors to DV? How and why women as victims are submissive or resistive to DV?

The interviews were usually of 1 or 2 hours duration spreading across multiple sessions carried in the months of April and May 2014. All the interviews were carried out in the author's residence as per the desire of the respondents. The recorded interviews were translated and transcribed simultaneously by the author herself with the application of open access transcribe software. The transcripts were later on read out to the respondents and only after their final approval, it was analysed on the basis of certain themes focusing on the objectives of the study. These women were purposively selected as the author was aware of their abusive lives. As oral history, method was applied to probing the experiences of their abusive lives of these women, through unstructured interview schedule, it provided indepth and a rich body of literature, for which only five women were interviewed for the study. To maintain the confidentiality of the identity of the respondents, fictitious names are used.

The study area is Guwahati, which is the largest urban area of the north-eastern region of India and has a population of 9.6 million (Census of India, 2011) and has been attracting people from the surrounding areas. It is located on the crescent shaped south bank of the river Brahmaputra in the Kamrup district, Assam, covering an area of 298. sq. km. It holds a commanding position in the form of the gateway of the North East India. Guwahati as an administrative and commercial city occupies a unique position in the capital cities of the region and provides better economic and social opportunities as compared to the surrounding rural areas. On the contrary, such opportunities also create opportunities to specific crimes specific to urban areas and are perceived as a space of fear (Bhattacharyya, 2015). It may expose women to various forms of harassment once they come out from their homes (Padhee, 2012; Vauquline, 2007; Vauquline, 2013). As reported in the NCRB (Table 2), that the overall reported cases of DV (torture by husband and in-laws) has increased phenomenally in Assam during the recent years and Guwahati as an urban centre reports the highest in the region (Vauquline, 2007).

\section{Findings}

\section{Types of Violence and Submissive Attitudes of the Victims}

DV are of different types but they are broadly categorised as physical, mental and physiological and sexual violence in this study (Das et al., 2015a, forthcoming). From the narratives of the women, it is found out that both physical and mental violence are common among these women and none of them have stated about sexual violence.

Anuja Sharma reveals her experiences of violence through the narratives.

Everything was going on smoothly in my life until my daughter was 9 months. After my marriage, I used to live most of the time with my own parents since I am the eldest child of the family and my father was frequently not keeping well. Things started changing gradually when I returned back home (in-laws) after my father expired. Few days after my return, my husband stated that he wants me to stay in the village with my in-laws and raise my daughter there. But I insisted that I would stay with him wherever he was posted as his was a transferable job. Irritated with my refusal, he kicked me hard on my back and I fell down hard on the floor. Actually, he was angry with me for a long time as I refused previously also to live with my in-laws in the village. He was unwilling to take us to his official quarter. On another occasion, he again kicked me. 


\begin{tabular}{|c|c|c|c|c|c|c|c|}
\hline $\begin{array}{l}\text { Name } \\
\text { and } \\
\text { Relation }\end{array}$ & Age & Religion & Caste & Community & $\begin{array}{l}\text { Education } \\
\text { Qualification }\end{array}$ & $\begin{array}{l}\text { Marital } \\
\text { Status }\end{array}$ & Married For (in years) \\
\hline Anuja & 31 & Hinduism & General & Assamese & Post Graduate & $\begin{array}{l}\text { Was living separately } \\
\text { while the interview } \\
\text { was conducted }\end{array}$ & 9 \\
\hline Anuja's Mother & 54 & Hinduism & Schedule Tribe & Bodo & Under Graduate & Widow & 35 \\
\hline Susmita Majhi & 25 & Hinduism & $\begin{array}{l}\text { Other Backward } \\
\text { Community }\end{array}$ & Tea Tribe & Illiterate & Married & 10 \\
\hline $\begin{array}{l}\text { Faguni Majhi } \\
\text { (Susmita's Mother) }\end{array}$ & 45 & Hinduism & $\begin{array}{l}\text { Other Backward } \\
\text { Community }\end{array}$ & Tea Tribe & Illiterate & Widow & 30 \\
\hline Minu & 51 & Hinduism & General & Assamese & Under Graduate & Married & 26 \\
\hline
\end{tabular}

\begin{tabular}{|c|c|c|c|c|c|c|c|c|c|c|c|c|}
\hline Year & 2014 & 2013 & 2012 & 2011 & 2010 & 2009 & 2008 & 2007 & 2006 & 2005 & 2004 & 2003 \\
\hline No of Cases Registered & 9626 & 8636 & 5407 & 5246 & 5410 & 4398 & 3478 & 3000 & 2548 & 2206 & 1945 & 1808 \\
\hline
\end{tabular}


My daughter was suffering from high fever. He asked me to put water and oil on her forehead because my mother-inlaw wants me to do so. I did not pay heed to his instructions thinking that it might make my daughter's condition worse. Therefore, for not listening to him he kicked me very hard. The pain was there for a very long time and I had to go to the doctor for it later. The pain erupts at times even now.

She mostly went through psychological (mental) violence. There were insulting words by her husband to hurt her sentiments and make her feel low.

He used to tell me, "Even though you consider yourself to be a Brahmin, you are not (her father belonged to Brahmin caste). ${ }^{8}$ You have more of Bodo blood in yourself (her mother belongs to Bodo tribe). If you feel that you belong to a superior class why couldn't you get for yourself a Brahmin groom?" This was how he used to insult me most of the time. I used to wonder why he says all these because his mother is a Bodo and his father is a Rabha. ${ }^{9}$ My husband often used to insult me by saying, "just because you are wearing a makhela chadar (a traditional attire of Assamese community), do you think your Bodo blood will vanish from you?". All these abuses used to make me feel that he never liked my family members and had any respect for them. All these arguments used to make me feel very low and humiliated.

Faguni Majhi is one of the women who experienced the extreme forms of physical violence.

She initially confessed that she was physically assaulted only once by her husband. But later on, her narratives disclosed that it was almost a daily affair.

\footnotetext{
${ }^{8} \mathrm{Brahmins}$ are the highest and the first of the four Hindu castes.

${ }^{9}$ Rabhas are the tribal community leaving in Assam, India.
}

My husband first hit me when my first son was born. I ran away to my brother's place. Later on, he came to fetch me and I came along ....after that, it happened a number of times. He used to get drunk and beat me with whatever he finds within his reach. I then leave my kids and run for my life to my bother-in-laws house and stay there (who used to stay next door). One day he chased me with a sharp knife. I took one huge leap, and jumped over a bamboo fence, as I was young then and ran across the paddy fields and hid myself in a bamboo grove. Those fears are still there. Even today when I think about those days I can feel my body shivering.'

These findings corroborate with previous research conducted in India and other countries such as Bangladesh, China, Cambodia, Indonesia, Sri Lanka, and Papua New Guinea (Das et al., 2015a, forthcoming; Fulu et al., 2013; Jewkes et al., 2013; Ragavan et al., 2015). In the other cases too, the women initially denied of any form of physical violence. Initially, they mentioned that their husbands physically assaulted only once. However, the on-going conversations unfolded instances of violent atrocities. Again, none of these women has confronted their husbands physically and they had their own explanations regarding their submissive attitudes.

Faguni explains,

I never hit back. If I would have hit him back, he would have become more violent, he might have held my neck tight..., and my kids were so small. I used to tell him, do not hit me... our kids are so small. I was afraid of him because his hands were very strong.

Minu states,

No nono... never. It is a sin because he is elder to me and after all he is my husband and I have to respect him. He used to tell me many things but I never retaliated. I used to get angry, very 
angry and also feel like hitting back but I could not. My conscience did not allowed me do so. I used to find it difficult to do it.

Anuja confessed,

At times, I felt like hitting him. But something within me did not allow me to do so. It is not fear though. I felt it was just not right to hit him back.

\section{Agents of Socialisation}

Most of these women were taught certain forms of social values by their mothers or by their mother(s)-in-law or by some female members of the family except for Anuja where her father played a proactive role in socialising her. They were reminded of the values either that a girl is supposed to follow from time to time or they have learnt by observing their mother, sister or the other members of their family. The family played a distinctive role and was a primary place of socialisation for all of them (Bhattacharyya, 2009; 2013; 2015; Chakrabarty, 2002).

Anuja narrates,

I got married when I was 22 and maybe I took some time to understand the values of these traditions. My parents taught me to be truthful and be a good person. They taught me to an active member of the society. They were not bothered about the traditional things about dress, domestic works and what not...'

In the said context, Anuja's mother emphasizes and illustrates about her own life.

She (Anuja) has seen how I lead my life and have learnt all these from me. In this circumstance, how can she be different from me? All these virtues...did not they go to her? Did not she learn all these from her childhood? She has seen and learnt how she is supposed to stay with her in-laws, in a joint family. She has seen all these. I did not have to teach her separately...all these are values and learning. One need not teach them separately from books. These are taken over by the daughters and sons. I too grew up in a very large joint family and in this same way, I learnt these values from my mother, aunty and from my elder sisters. I used to enact what they used to do and now I have seen my children enacting those roles and have learnt them.'

For Minu her mother was her mentor and says

She never taught us anything particular but I learnt on my own having grown up in that environment. Do not know how? I used to hear my mother telling or giving advice to some people when they used to visit her house and thereby, I learnt. I learn all these from my mother. I grew up in her shadow and her principles. Even today when I have to do anything, I think about her first and then act.'

Susmita (Faguni's daughter) had totally a different story to tell. She grew up in a house where she used to work as a house cleaner. She lived with them from the age of seven and returned home at eighteen years of age. The lady owner of the house had immense influence on her and narrates:

Where I used to work, there I used to see how the wife treat her husband and learnt from her. She also taught me many things. I did not realise it initially, but later on, it had a strong imprint on my mind.

\section{Social Understanding of the Power Relations}

In all these cases, strong power relations are observed where women are always placed in the inferior positions, irrespective of race and ethnicity. These power relations stems from patriarchal practices and social mores that remain deeply entrenched within Assamese society (Bhattacharyya, 2009; 2013). Anuja is living in her natal home for the past 5 years. Her mother and her close relatives do not want her to return to her husband's place fearing that she might have to face severe physical abuses and her life could be a threat. However, 
Anuja is constantly pressurised by the members of the society in different ways to go back to her in-laws. She is made to realise that she is breaking the traditional norms of the society.

I stopped putting sindur on my forehead. ${ }^{10}$ I do my work independently all by myself; work in the media (need to stay till late hours at night). I started wearing clothes according to my own convenience (such as salwar kamez). ${ }^{11}$ I stopped putting sindur because it is convenient for me to work otherwise I need to answer many questions, "why I am living with my parent? Where is your husband?", etc. ... Now my sindur has become a burden for me. If I do not put people ask me "why" and if I put it, I face questions from people, "How can I?" When I go to attend, any social functions people enquire about my husband...intentionally or unintentionally I have no idea....as if I do not have any identity of my own!

On the other hand, Anuja's mother also has to face many questions posed by the society for keeping her married daughter along with her granddaughter at home.

In every step, she makes people see fault in it and she also feels it. People do not like to talk to her or avoid her. So she is now breaking down physiologically. My neighbours have stopped talking to me too because I did not follow what they said. Once, one of my neighbours called me to her house and instructed me to send her back to her in-laws. They said "they kill her, beat her it is their problem and it is their wish... you send her back. You are creating problem for your son and his future. You will face problems to get your son married and also to run the family then. Let them keep her in

\footnotetext{
${ }^{10}$ Sindur is red vermilion put by married Hindu women on the parting of her hair to signify that her husband is alive and it is also believe to bring long life of the husband.

${ }^{11}$ Salwar kamiz is traditional attire but is generally not worn by the married Assamese women.
}

whatever way they want. She is a married girl... why are you keeping her with you? It doesn't look nice." Do people of modern age talk like this'?

Such attitudes do raise the question of modernity in Indian context (Bhattacharyya, 2009; 2013; Chakrabarty, 2002). This research however does not engage the debate of modernity in detail, but for the purpose of this research, it can simply be understood as the 'cultural practices specific to Indian society in general (and here, Assamese society in particular) (Bhattacharyya, 2009; 2013; 2015; Chakrabarty, 2002).

Minu lives with her abusive husband fearing social ostracism that may crop on her and her daughter.

Very soon I will have to get her (my daughter) married. Her father's identity will be required then. What answer will I give then? Father plays an important role in a child's life. It was for these reasons; looking at the future of my daughter, I continued living with my abusive husband. My sisters used to tell me that after a girl gets married, her natal home do not have responsibilities towards her. Our house is a respected one in the village and if anybody from the village say, "Oh! She has come back to her natal home" I will die of shame...it is like going to the hell. I cannot bear it. I have lots of selfrespect'.

Susmita, the daughter of Faguni, was taught to accept the power relations for the peace and harmony of the family.

The lady owner used to tell me that if I respect my husband, my married life will always be blessed one and everything will go well with me. Our home will be in peace and I will be in peace. But if I do not know how to respect him, my house will never be in peace and me too. 


\section{The Power Relations: The Unequal Power Structure}

The power relations between the husband and the wife are an unequal one and it used to be governed by the social believes attached to it. As the findings suggests, the women of the research have learnt them either through observations or from their social customs. All of them believed and sincerely abided them as doctrine truths except for Anuja.

Susmita believed that:

I should always be small in front of him. I am younger to him by age and pay him respect as a husband. I was told to cover my head with a veil in front of the male members and if I don't I am not respected

Falguni followed,

According to our societal norms, we are not supposed to hit our husband but I can be beaten by him. Our societies say that the husband is bigger/elder and I am younger than my husband is so I should stay under his feet. According to our tradition, my mother-in-law and my husband can beat me. The elders of our society taught me all these when we got married. Then I had to salute my husband as "Ram". It is known as "Ram Salam". I have also seen my brothers and my sisters following them. I will be punished by the society if I hit him. He feeds me and so if I hit him my hands will become rotten/ become handicap.

Minu abided that:

Once I am married off, it is done. Even if I am beaten, bruised I should live in my husband's place. She (her mother) used to think that he (my father) is her god on earth so I too believe my husband to be the same like my mother. My mother used to tell me, "In your husband's place even if you have to shed tears you have to live with him. No matter how much hardship, you have you will always have to stay with your husband.

\section{Discussion}

The inter-generational study of DV through oral history method reflected that DV continued from one generation to another only in the case of Faguni Majhi and her daughter and both of them are illiterate. When we draw our attention to the forms of violence experienced by the victims, it provides another dimension to DV; the severity of violence decreases along with the educational qualifications of the victims (Vauquline, 2007). This finding is in contrast to the observations made by Das et al. (2015 a, forthcoming) in their research in Sylhet, Bangladesh where they have shown that women with higher education and financial independence also faced severe forms of DV.

Severe forms of physical violence were encountered by both Faguni and her mother, followed by Minu. Anuja was mostly mentally abused and on two occasions was physically assaulted. Whereas it was Anuja, who resisted to the abuses and decided to come out from the abusive situation even though the forms of violence she encountered were not of severe forms. Again, it was Anuja, who disclosed about her abusive life without much hesitation. The rest of the respondents initially stated that physical violence occurred in their conjugal life only on very few instances and revealed about them from their second interactive sessions onward. It was observed during the interviews that all the victims (including Anuja) were gripped with deep sense of humiliation while narrating the instances of physical violence.

As stated above, I repeat, the values, regarding the relationship between the spouses, embedded with strong patriarchal norms were learnt by these women through observations and by being a part of the system (the family). Leela Dube (1988: 11) states that, "[g]ender roles are conceived, enacted and learnt within a complex of relationships'. Family happened to be the most active and the strongest training ground for these socialisation processes, which sets the rules of acceptances (Bhattacharyya, 2009; 2013; Chakrabarty, 2002). Interestingly, except for Anuja, in all the cases female members (mother, aunty, sister, etc.) of the 
family were the agents of socialisation. From the narratives of Anuja, it reveals that her father played an important role in her life and nurtured within her the egalitarian values from her childhood onwards (self-independent, selfconfidence, being assertive, etc.) which later on encouraged her to come out from her abusive life. However, she was perceived as 'different' by her husband, her in-laws and her neighbours too as she did not fit into the norms set by the society (submissive, docile, dependent, etc.) for which she felt and was treated as an outcaste more so during social functions (marriage, festivals, rituals, etc.).

From the narratives, it is observed that all the respondents underwent more or less similar yet different processes of socialisation and in different social setup. However, they are all patriarchal in nature where women are taught to be submissive and placed in inferior positions (Bhattacharyya, 2009, 2013; 2015). Except for Anuja, none of these women ever resisted to any forms of violence perpetrated on them. Rather they gave varied reasons to their submissive nature, such as fear, spiritually intertwined explanations (sin) and values, which were patriarchal in nature.

There are various ways in which the power relations are explained winding social as well as spiritual rudiments to its understanding. Not abiding the social norms and the traditional practices are often considered as violation of the spiritual practices too and associated as sins. It is considered as a sin to raise a hand against the husband as he is expected to be treated as God (Pati Parmeshwar) in certain communities (Bhattacharyya, 2015). From the life stories of all these women, the various social practices followed by married Hindu women are brought to light. They are the different forms of patriarchal practices carried forward from one generation to another and hold great significance to majority Hindu women. Considering the girl child as the temporary member of the natal family and the boy child as a permanent, one has its consequences on DV too (Bhattacharyya, 2009; 2013; 2015). A married woman becomes shelter less and has no place to turn to during such situations. She becomes a property of her husband and in-laws once she gets married (Bhattacharyya, 2015; Das et al., 2015a, forthcoming). She is not expected to live for a longer duration in her natal home after she is married (Bhattacharyya, 2009). Association of father's identity with any rituals, more so during marriage of the daughter, plays a significant role and considered essential. These believe are practiced religiously by majority of the Indian women and are patriarchal in nature. These practices, believes and values created power relations between the husband and wife and often discouraged the women to come out from their abusive marital relations (Das et al., 2015 a, forthcoming).

\section{Conclusion}

The study reveals that because of the power relations that are unequal and patriarchal in nature, DV occurs. The husbands feel that they have the right to abuse their wife and the wife on the other hand, follow the notions of tolerance and self-restraints. These are rooted in the 'consciously-cultivated feminine role', which are in most instances rooted and legitimised by cultural practices and ideologies (Bhattacharyya, 2009, 2013; 2015; Chakrabarty, 2002; Dube, 1988). In all these cases, the women are considered as a property of the family and are treated as an object, have no say of their own. Their actions are patronised by the social values and the traditional norms, which are patriarchal in nature and is institutionalised by the society. These put women in the disadvantaged positions and at the receiving ends. When women resist to these violence, it becomes more intensive and brutal in nature (Susmita's case). It also becomes difficult for the women to come out from it to a lead a better life because of the social ostracism that pushes them back to their abusive situations. Deeper insight into the life of ethnic groups (Anuja, Faguni and Susmita) depict that DV equally exists among them and patriarchal values governs their life largely. Patriarchal values creating power relations among intimate relations is unacceptable and 
only if it fades off from the society DV will cease to exist in the society (Vauquline, 2007). Along with the strong legislations, educating the society and the future generations about gender relations and the various aspects of it, from very childhood will definitely play a vital role to combat VAW.

\section{References}

AhmedGhosh, H. (2004). Chattels of Society Domestic Violence in India, Violence against Women, 10 (1), pp. 94-118.

Anderson, K. L. (1997). Gender, Status, and Domestic Violence: An Integration of Feminist and Family Violence Approaches, Journal of Marriage and Family, 59 (3), pp. 655-669.

Arthur, C. and Clark, R. (2009). Determinants of Domestic Violence: A Cross-National Study, International Journal of Sociology of the Family, 35, pp. 147-167.

Assam Online Portal, Available at: http://online.assam.gov.in/web/populationcensus/census2011

Babbel, S. (2011). Domestic violence is a Pervasive, Too-common Form of Abuse. Somatic Psychology, May 27.

Bhattacharyya, R. (2015). Understanding the Spatialities of Sexual Assault against Indian Women in India, Gender, Place and Culture, 22 (9), Routledge, Taylor and Francis Group, pp. 1340-1356, http://dx.doi.org/10.1080/0966369X.2014.969 684

Bhattacharyya, R. (2013). Are We Empowered? Stories of Young Indian Working Women, Saarbrücken, Germany: Lap Lambert Academic Publishing.

Bhattacharyya, R. (2009). Examining the Changing Status and Role of Middle Class Assamese Women: Lessons from the Lives of University Students, Doctoral Dissertation, University of Newcastle upon Tyne, United Kingdom.

Bhattacharyya, R., Vauquline, P. and Singh, S. (2011). Towards a Socially Sustainable India: An Analysis of National Rural Employment
Guarantee Scheme, 2006. In S.K. Singh, Raj Kumar, H.P. Mathur, N.B. Singh and V.K. Kumar (eds). Energy Resources, Alternative Search and Sustainable Development, New Delhi: Shree Publishers, pp. 73-88.

Bhattacharyya, R. and Vauquline, P. (2013). A Mirage or a Rural Life Line?: Analysing the Impact of Mahatma Gandhi Rural Employment Guarantee Act on Women Beneficiaries of Assam, Space and Culture, India, 1(1), pp. 83101.

Biber, S. N. H. and Leavy, P. (2011).The Practice of Qualitative Research $2^{\text {nd }}$ edition, London: Sage. pp. 131.

Bowker, L. (1983). Beating Wife-beating. Lexington, MA: Lexington.

Brush, L. D. (1990). Violent Acts and Injurious Outcomes in Married Couples: Methodological Issues in the National Survey of Families and Households, Gender and Society, 4 (1) Sage pp. 56-67.

Campbell, A. (1993). Men, Women and

Aggression, New York: Basic Book

Chaudhary, S. (2013). Domestic Violence in India, Journal of Indian Research, 1 (2), AprilJune.

Clegg, S. R. (1975). Power, Rule and Domination, London, Routledge and Karen Pual, pp. 57.

Connell, R. W. (1987). Gender and Power: Society, the Person and Sexual Politics. Stanford, CA: Stanford University Press.

Crowley, H. (1999). Women's Studies: Between a Rock and a Hard Place or Just Another Cell in the Beehive? Palgrave Macmillan Journals, pp. 131-150, http://www.jstor.org/stable/1395578

Chakrabarty, D. (2002). Habitations of Modernity: Essays in the Wake of Subaltern Studies, Chicago: The University of Chicago.

Dalal. K. and Lindqvist, K. (2012). A National Study of the Prevalence and Correlates of Domestic Violence Among Women in India, Asia Pacific Journal of Public Health, 24 (2), pp. 265277. 
Das, T. K., Alam, F., Md., Bhattacharyya, R. and Parvin, A. (2015a). Causes and Contexts of Domestic Violence: Tales of Help-seeking Married Women in Sylhet, Bangladesh, Asian Social Work and Policy Review, 9 (2), 163-176, doi:10.1111/aswp.12055

Das, T., Bhattacharyya, R. Alam, F. Md., and Parvin, A. (forthcoming). Nature and Prevalence of Domestic Violence: Analyzing the Experiences of Help Seeking Abused Women in Sylhet, Bangladesh, Journal Social Change.

Dobash, R. P., and Dobash, R. E. (1979). Violence against Wives: $A$ Case against the Patriarchy. New York: Free Press.

Domosh, M. and Seager, J. (2001). Putting Women in Place: Feminist Geographers Make Sense of the World, New York: Guilford Press.

Dwyer, C. and Limb, M. (2001). Introduction: Doing Qualitative Research in Geography. In Dwyer.C and Limb. M (eds.), Qualitative Methodologies for Geographers: Issues and Debates, London: Arnold, pp. 1-20.

Dube, L. (1988). On the Construction of Gender Hindu Girls in Patrilineal India, Economic and Political Weekly, 23 (18) April 30, pp. WS 11-WS 15. Retrieved from http://www.jstor.org/stable/4378429

Encyclopedia Britannica, Available at: http://www.britannica.com/EBchecked/topic/3 63055/Manu-smriti

Emery, R. E., and Laumann-Billings, L. (1998). An Overview of the Nature, Causes, and Consequences of Abusive Family Relationships: toward Differentiating Maltreatment and Violence, American Psychologist, 53, pp. 12135.

Fagan, J. (1996). The Criminalization of Domestic Violence: Promises and Limits, Research Report, U.S. Department of Justice Office of Justice Programs, National Institute of Justice.

Ferree, M. (1990). Beyond Separate Spheres: Feminism and Family Research. Journal of Marriage and the Family, 52, pp. 866-884.
Foucault, M. (1977). History of Sexuality, 1, Victoria, Penguin Books, pp. 92-95.

Fulu, E., Roselli,T. and Garcia-Moreno, C. (2013). Prevalence of and Factors Associated with Male Perpetration of Intimate Partner Violence: Findings from the UN Multi-country Cross-sectional Study on Men and Violence in Asia and the Pacific, The Lancet Global Health1: e187-e207.

Gelles, R. J. (1993). Through a Sociological Lens: Social Structure and Family Violence, R. J. Gelles\& D. R. Loseke (eds.), Current Controversies on Family Violence, Newbury Park, CA: Sage. pp. 31-46.

Gelles, R. J., and Straus, M. A. (1988). Intimate Violence: The Causes and Consequences of Abuse in the American Family. New York: Simon \&Schuster.

Ghosh.B, Choudhuri, T. (2011). Legal Protection against Domestic Violence in India: Scope and Limitations. Journal of Family Violence, 26 (4), pp. 319-330.

Ghosh, D. (2007). Predicting Vulnerability of Indian Women to Domestic Violence Incidents. Research and Practice in Social Sciences, Vol.3, No.1, pp 48-72.

Gluck, S. B. (2011). Has Feminist Oral History Lost Its Radical/Subversive Edge? Oral History, 39 (2), Past and Present, pp. 63-72.

Government of India, Ministry of Home Affairs, Lok Sabha, Unstarred Question No.388, http://mha1.nic.in/par2013/par2013-pdfs/ls060813/388.pdf

Hassan, Yasmeen. (1995): The Haven Becomes Hell: A Study of Domestic Violence in Pakistan, Special Bulletin, Lahore: ShirkatGah.

Hart, B. J. (1991). Legal Advocacy against Domestic Violence http://www.mincava.umn.edu/documents/hart /legal/legal.pdf

Hartsock, N. (1999). Foucault on Power: A Theory for Women, Feminism/Postmodernism (Thinking Gender), Linda. J. Nicholson (ed.), New York: Routledge, pp. 164. 
Hesse, S. N. and Leavy, B. P. (2011). The Practice of Qualitative Research, 2nd edition, Sage.

Jaisingh, I. (1995): "Violence against Women: The Indian Perspective" in J Peters and A Wolper (eds), Women's Rights, Human Rights, New York: Routledge.

Jewkes, R., Fulu, E., Roselli, T. and GarciaMoreno, C. (2013). Prevalence of and Factors Associated with Non-partner Rape Perpetration: Findings from the UN Multicountry, Cross-sectional Study on Men and Violence in Asia and the Pacific, Lancet Global Health, 1:e208-e218.

Johnson, M. P. and Ferraro. K. J. (2000). Research on Domestic Violence in the 1990s: Making Distinctions, Journal of Marriage and Family, 62 (4), pp. 948-963.

Karlekar, M. (2008).Domestic Violence, In Mary. E. John. (ed.), Women' Studies in India, London: Penguin Books. pp.241.

Koenig, M A et al (2006), Individual and Contextual Determinants of Domestic Violence in North India, American Journal of Public Health, 96, pp. 132-38.

Krishnan, S. (2005). Gender, Caste, and Economic Inequalities and Marital Violence in Rural South India, Health Care for Women International, 26 (1), pp. 87-99.

Majors, R., and Billson, J. M. (1992). Cool Pose: The Dilemmas of Black Manhood in America. New York: MacMillan.

Martin, D. (1976). Battered Wives. New York: Pocket Books.

Messerschmidt, J. (1993). Masculinities and Crime: A Critique and Reconceptualization of Theory. Lanham, MD: Rowman \& Littlefield.

Miller, Barbara D (1992): Wife-beating in India: Variations on a Theme, D. A. Counts, J. K. Brown and J. C. Campbell (eds), Sanctions and Sanctuary: Cultural Perspectives on the Beating of Wives, Boulder: Westview Press, pp. 173-84.

National Crime Records Bureau, Ministry of Home Affairs, Government of India. www.ncrb.gov.in
Padhee, A. (2012 30 July). Women's

Experiences of Living in a City: A Study into the Experiences of Safety and Unsafety amongst Single Indian Women Living in London, MPhil Dissertation (unpublished), Girton College, UK. http://www.academia.edu/3398391/Womens_ experience s_of_living_in_a_city

Pilcher, J. and Whelehan, I. (2004). Fifty Key Concepts in Gender Studies, London: Sage.

Ragavan, M., lyengar, K. and Wurtz.R. (2015). Perceptions of Options Available for Victims of Physical Intimate Partner Violence in Northern India. Violence against Women, 21 (5). pp. 652675.

Safe Horizon: Moving Victims of Violence from Crisis to Confidence. Available at: http://www.safehorizon.org/index/getinvolved-14/making-violence-against-womenhistory-157/history-of-domestic-violence299.html

Samarasekera, U. and Horton, R. (2015). Prevention of Violence against Women and Girls: A New Chapter, The Lancet, pp. 385, 1480-1482.

Segal, L. (1990). Slow motion: Changing Masculinities, Changing Men. New Brunswick, NJ: Rutgers.

Stark, E ., and Flitcraft, A. H. (1996). Women at Risk: Domestic Violence and Women's Health, Thousand Oaks, CA: Sage.

Straus, M. A., Gelles, R. J., and Steinmetz, S. K. (1980). Behind Closed Doors: Violence in the American Family, Garden City, NY: Anchor.

Straus, M. A. (1987). The Conflict Tactics Scales: An Evaluation and New Data on Validity, Reliability, Norms, and Scoring Methods. Paper presented at the Annual Meetings, National Council on Family Relations.

The Life and Times of an Indian Homemaker, http://indianhomemaker.wordpress.com/tag/s aint-tulsidas-ramchaarit-manas/

Thompson, L. (1992). Feminist Methodology for Family Studies. Journal of Marriage and Family, 54 (1), pp. 3-18. 
Tracy, S. R. (2007). Patriarchy and Domestic Violence: Challenging Common

Misconceptions. Journal of the Evangelical Theological Society, 50 (3), pp. 573-594.

Umberson, D., Anderson, K., Glick, J., and Shapiro, A. (1998).Domestic Violence, Personal Control, and Gender. Journal of Marriage and Family, 60 (2), pp. 442-452.

United Nations. (2006). Ending Violence against Women: From Words to Action: Study of the Secretary General, United Nations Secretariat, Department of Economics and Social Affairs, Geneva, Switzerland.

Vauquline, P. (2007). Gender-related Crimes in Greater Guwahati Urban Area, (Unpublished PhD thesis).North Eastern Hill University, Shillong.

Vauquline, P. (2013). Darker Side of Urbanisation: Incidences of Sexual Harassment in Guwahati, Asian Journal of Research in Social Sciences \& Humanities, 3 (10), pp. 10-17.

Walker, L. (1984). The Battered Woman Syndrome, New York: Springer.

Watto, S.A. (2009). Conventional Patriarchal Ideology of Gender Relations: An Inexplicit Predictor of Male Physical Violence against Women in Families, European Journal of Scientific Research, 36 (4), pp. 561-569.
Weber, M. (1968). Authority and Rationality in Max Weber Economy and Society edited by Guenther Roth and Ckus Wittich, New York: Bedminster Press Incorporates.

West, C. and Zimmerman, D. (1987).Doing Gender, Gender and Society, pp. 1, 125-151.

Wolfe, D. A. and Jaffe, P. G. (1999). Emerging Strategies in the Prevention of Domestic Violence: The Future of Children, Domestic Violence and Children, 9 (3), pp. 133-144.

Women's Aid Federation of England.http://www.womensaid.org.uk/domes tic-violencearticles.asp?section $=00010001002200410001 \&$ itemid $=1280$

Yeasmeen, N. (2014). Domestic Violence In India (Socio-Legal Aspects) With Special Reference To Protection Officer Under DVP, Act: How Far They Are Successful In Providing Solace To The Victims? Journal Of Humanities And Social Science (IOSR-JHSS), 19 (10), pp 0814. www.iosrjournals.org.

Yllo, K. (1993). Through a Feminist Lens: Gender, Power, and Violence. In R. J. Gelles\& D. R. Loseke (Eds.), Current Controversies on Family Violence, Newbury Park, CA: Sage. pp. 47-62. 